\title{
Deep hard rock mining and rock mechanics challenges
}

\author{
E. Nordlund Division of Mining and Geotechnical Engineering, Luleå University of Technology, Sweden
}

\begin{abstract}
Mining at depth is associated with high stress magnitudes and often serious ground control problems. Two different extreme conditions: (a) hard rock and seismic problems, and (b) altered weak ore or weak ore contact zones in a hard host rock mass resulting in large deformations and squeezing conditions, are typical for deep mining in Sweden. A research programme focused on rock support design for deep mining conditions has been conducted at Luleå University of Technology, Division of Mining and Geotechnical Engineering, since 2009. The objective of the research is to improve the understanding of the (i) rock mass response and the rock support system performance, and (ii) the interaction between the rock mass and the rock support system when mining at increasing depth. The programme comprises field monitoring in three mines, looking at large-scale dynamic loading of rock support systems, numerical analyses of different phenomena, failure mechanisms, and details in the rock mass-rock support system interaction. The paper gives examples of activities and programme results. The programme has so far resulted in new knowledge and new questions. In order to improve the understanding of the rock mass-rock support interaction, details are important. Since the programme will run for a number of years, only a few sub-projects are finished and therefore the main conclusions are still not drawn.
\end{abstract}

\section{$1 \quad$ Introduction}

Mining of deep seated deposits is associated with high stress magnitudes, in many cases exceeding the strength of the intact rock, geological structures and the rock mass. Deep mining problems in Sweden are related to two different extreme conditions: hard rock and seismic problems, and altered weak ore or weak ore contact zones in a hard host rock mass resulting in large deformations and squeezing conditions. A research programme focused on deep mining problems is underway at the Luleå University of Technology (LUT), Division of Mining and Geotechnical Engineering. The programme started with a project sponsored by Vinnova (Swedish Governmental Agency for Innovation Systems), LKAB, Boliden Mineral AB, Hjalmar Lundbohm Research Centre (HLRC) and has continued with support from Centre of Applied Mining and Metallurgy (CAMM) at LTU and the 7th Framework project $I^{2}$ Mine. The objective of the research is to improve the understanding of the (i) rock mass response and the rock support system performance, and (ii) the interaction between the rock mass and the rock support system mining at increasing depth. The geomechanical conditions considered are squeezing/large deformations and seismicity. The work has comprised: (i) field monitoring in three mines, using cut-and-fill mining, rill mining (or Avoca method) and sublevel caving; (ii) seismic loading of rock support by blasting experiments in the Kiirunavaara Mine; and (iii) numerical analyses of different phenomena and failure mechanisms. This paper is a short summary of these research activities. As 2.5 years still remain of the research programme, some results are available, some activities are ongoing and some activities have not yet started. The paper presents an overview of the research activities and detailed information from some of the sub-projects.

\section{$2 \quad$ Field monitoring and tests}

Field monitoring has been carried out in three mines (Table 1). Tests $1 \mathrm{a}$ and $1 \mathrm{~b}$ were designed specifically for the project, Rock Support Systems in Interaction with the Rock; a sub-project within the Swedish Mining Research Programme sponsored by Vinnova and Boliden Mineral AB, LKAB and HLRC. Monitoring at the Kristineberg Mine, Test $1 \mathrm{a}$, involved a comprehensive instrumentation of cut \#4 of the stope $\mathrm{J10}-3$, and two additional tests in cut \#5 of stope J10-3 and cut \#1 of stope J10-4. The objective of Test $1 \mathrm{~b}$, in the Norra Alliansen orebody in the Malmberget Mine, was to monitor the deformations and the development of 
damage due to production/retreat on the levels above the instrumented crosscut. Instrumentation was installed in 2011-2012 during the development of the crosscut. Test 2 was carried out in the Norra Alliansen orebody in the Malmberget Mine during 2007-2009. It was evaluated and presented by Sundström (2010). This monitoring project will be revisited during 2013 as a part of the $I^{2}$ Mine project. The objective is to evaluate the measurements and observations from the ongoing programme's point of view and to include measurements conducted after 2009. Test 3 comprised two different monitoring activities. The first instrumentation was conducted as part of a general rock mechanics investigation. However, since this stope failed it was decided to incorporate it in the $1^{2}$ Mine project. A second instrumentation was conducted in another part of the orebody, aiming at monitoring the rock support performance and rock mass behaviour. Test 4 comprised the development of a large-scale dynamic field testing method of rock support for seismic conditions. This test was carried out in the northern part of the Kiirunavaara Mine during 2009-2013. In this paper, details of Tests $1 \mathrm{a}$ and $1 \mathrm{~b}$ will be presented with a focus on Test $1 \mathrm{a}$.

\section{Table 1 Field monitoring sites}

\begin{tabular}{lllll}
\hline Test & Type of Test & Mine/Orebody & Mining Method & Mining Company \\
\hline 1a & $\begin{array}{l}\text { Monitoring of mining } \\
\text { activities }\end{array}$ & Kristineberg/J-orebody & Cut-and-fill & Boliden Mineral AB \\
1b & & Malmberget/Norra Alliansen & Sublevel caving & LKAB \\
2 & & Malmberget/Norra Alliansen & Sublevel caving & LKAB \\
3 & & Garpenberg/Dammsjön & Rill mining & Boliden Mineral AB \\
\hline 4 & Large-scale dynamic tests & Kiirunavaara/Lake Ore & Sublevel caving & LKAB \\
\hline
\end{tabular}

\subsection{Kristineberg Mine}

The Kristineberg Mine is located in the municipality of Lycksele, Västerbotten county in northern Sweden. It is owned and operated by Boliden Mineral AB. Production started in 1940 and the mine is the oldest in the Boliden area. It is one of the deepest mines in Sweden with mining activities at depths of $850-1,320 \mathrm{~m}$ below the ground surface. The mine comprises a large number of orebodies, A-L orebodies, but most of them are depleted (Figure 1). The orebodies in the Kristineberg Mine are polymetallic and contain zinc, copper, lead, gold and silver as well as well-defined copper and gold ores. The primary mining method is mechanised overhand cut-and-fill mining where the backfill consists of waste rock and mine tailings. If the orebody is wider than $8 \mathrm{~m}$, a drift-and-fill method is used.

The Kristineberg deposit is situated in a wide zone of sericitised and chloritised quartz- and feldspar-rich acidic volcanites. The geology of the stopes $\mathrm{J} 10-3$ and J10-4 was obtained from borehole core logging and mapping. Three borehole fans were drilled along the strike of the stopes J10-3 and J10-4 in the sections Y825, Y850 and Y875 (Figure 2). The stratigraphic sequence immediately adjacent to the orebody is complex, with several rock types of varying thickness. The hangingwall (HW) and footwall (FW) rock is highly altered, and often very weak. 


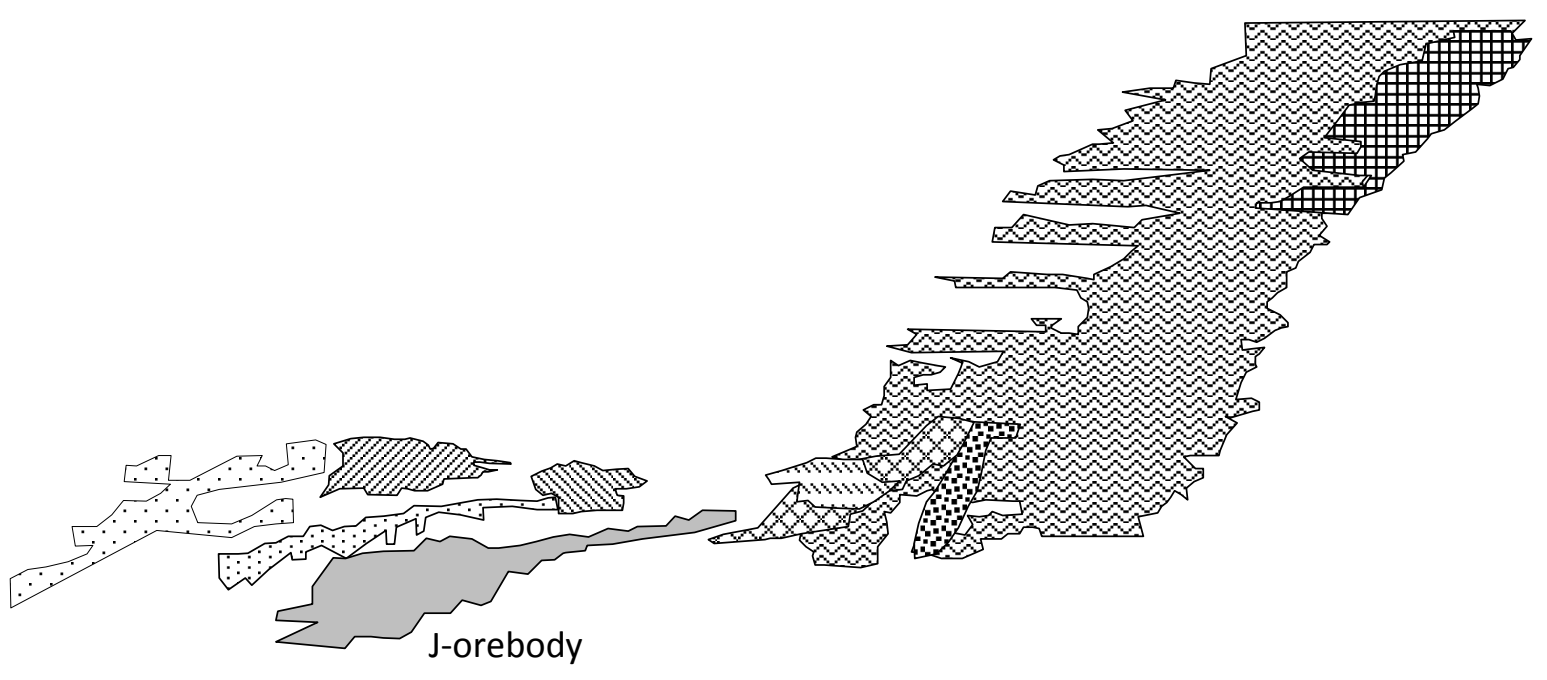

Figure 1 The Kristineberg Mine - vertical section (courtesy of Kristineberg Mine)

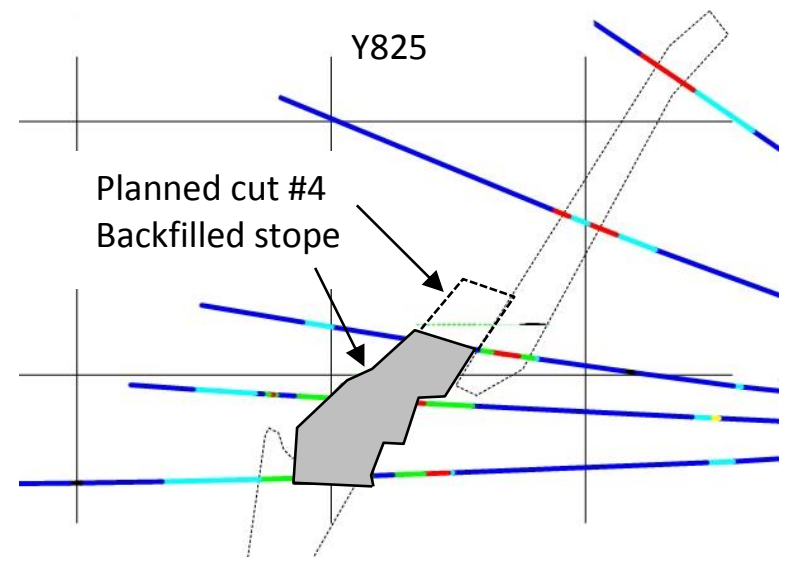

Cordierite - quartzite

- Sericite - quartzite

Chlorite - schist/talc

Chlorite - quartzite

Massive sulphide ore
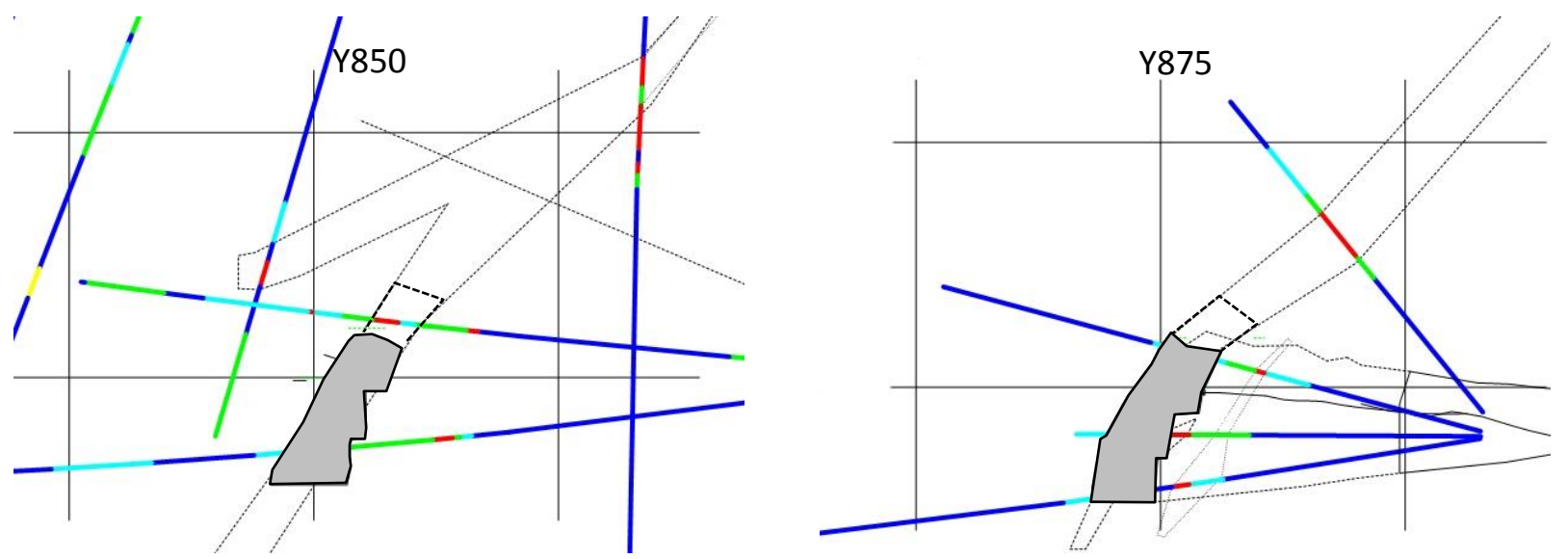

Figure 2 Geology and stope outline (courtesy of Kristineberg Mine) 
The general failure mechanisms observed in the Kristineberg Mine are shown in Figure 3 and described by Krauland et al. (2001). The induced major principal stress is oriented perpendicular to the orebody and punches the roof into the weak FW (chlorite-schist). The punching pushes the FW downwards and sliding occurs along the chlorite - host rock interface or along shear surfaces developed through the weak contact rock. Furthermore, the shear movements in the contact induce roof-parallel fractures causing a progressive failure in the roof along the contact until equilibrium is reached. The HW is often somewhat stronger than the FW and tends to deform in a bending manner inducing separation between the stronger host rock and the schist in the ore contact, or by separation along the foliation of the schist. Tensile fractures in the FW of the stope are also common.

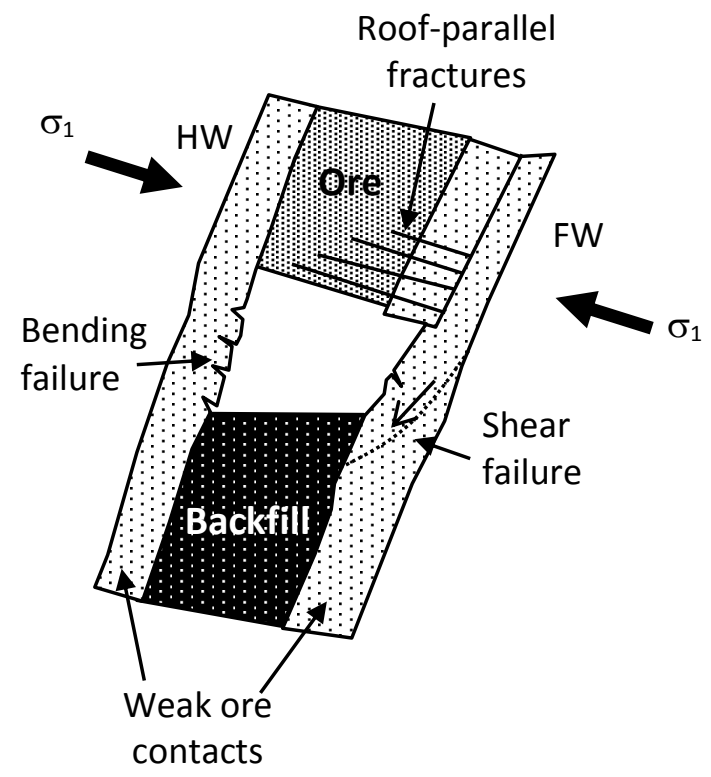

Figure 3 Typical failure mechanisms in the Kristineberg Mine (courtesy of Kristineberg Mine)

\subsubsection{Monitoring of stope J10-3, cut \#4}

A field monitoring project was conducted in 2010-2011. The main site was at the mining depth Z1,200 $\mathrm{m}$ in stope J10-3, cut \#4 (a 50 m long stretch) to the right from the access drift (Figure 4).

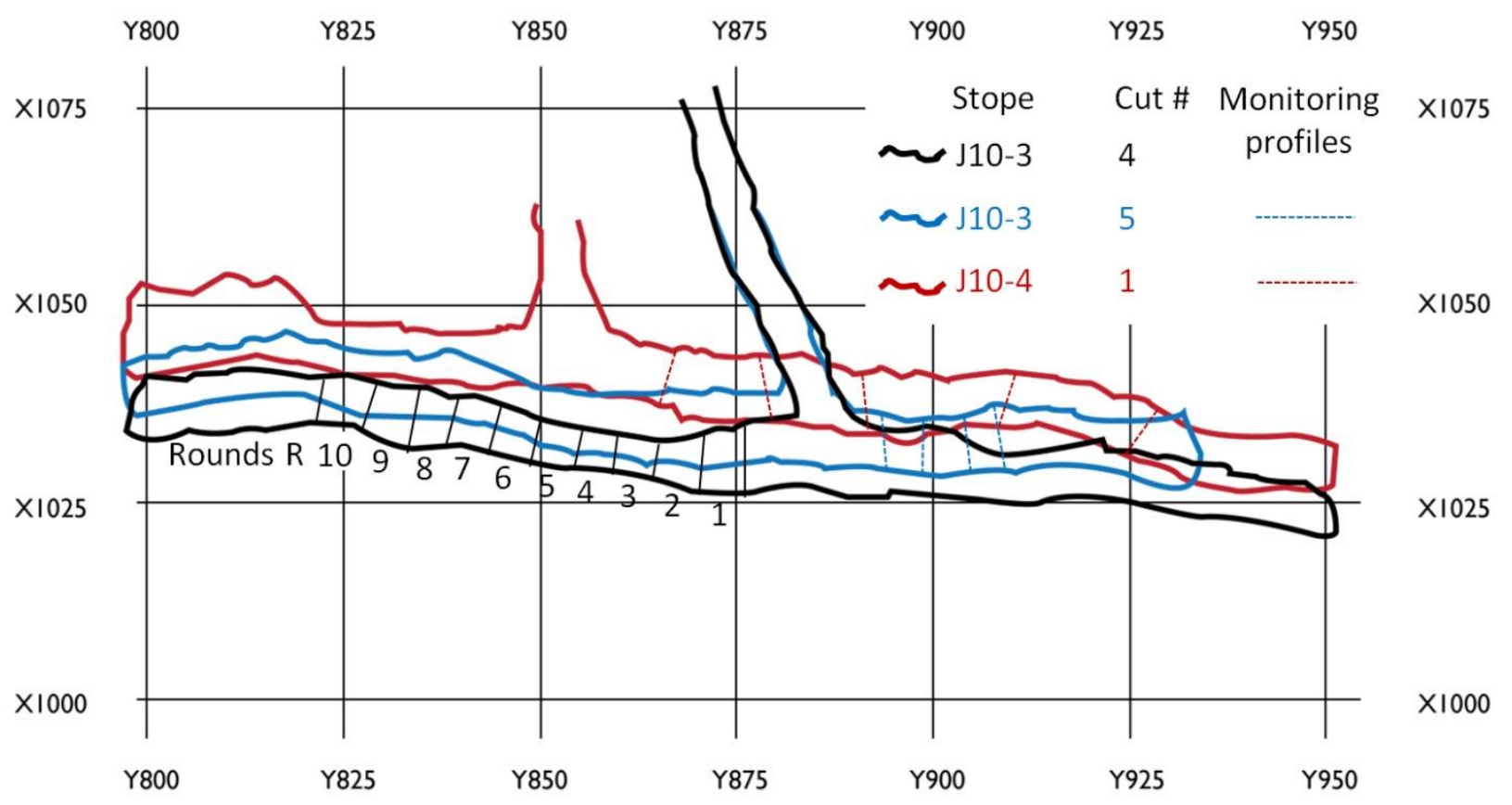

Figure 4 Monitoring sites at the Kristineberg Mine 
The test cut was located between the mine coordinates Y825 and Y875. Cut \#4 was approximately $5.8 \mathrm{~m}$ high and $5.5 \mathrm{~m}$ wide. Complementary monitoring was carried out in stope J10-3, cut \#5 and J10-4, cut \#1 (just above cut \#5), to the left from the access drift. The objective of the monitoring was to study the interaction between the rock mass and the rock support and to evaluate the D-bolt. Therefore, the bolt type installed was alternated every section between standard rebar and D-bolt. The rock support in the rebar sections comprised $2.7 \mathrm{~m}$ long, $20 \mathrm{~mm}$ diameter rebars in a $1 \times 1 \mathrm{~m}$ pattern. In the D-bolt sections, $2.7 \mathrm{~m}$ long D-bolts were installed in a $1 \times 1 \mathrm{~m}$ pattern. The surface support was $50 \mathrm{~mm}$ thick shotcrete reinforced with Dramix 35/65 (36 kg/m $\mathrm{m}^{3}$ of shotcrete). The monitored area in stope J10-3, cut \#4 consisted of ten blasting rounds (R1-R10). As evident from Figure 5, the shape of the stope was very irregular, especially since cut \#4 was translated with respect to the first three cuts. A schematic view of the conducted monitoring is shown in Figure 5. No measurements were recorded for the first two to three rounds closest to the drift entrance. The measurement sections (S1-S10) were located in the middle of each round, and comprised: (i) extensometers in the roof and both walls at S3:4 and S6:7; (ii) total station measurements of the stope surface at S3, S3:4, S4, S6, S6:7, and S7; and (iii) tape extensometer measurements between walls at each section. The project also included borehole camera surveying to monitor the development of damage inside the wall. The extensometers were $6 \mathrm{~m}$ long MultiPoint Borehole Extensometers (MPBX) with continuous logging (Detect-6EX). The accumulated deformation of the walls and roof in the monitored stope by means of extensometers increased with time.

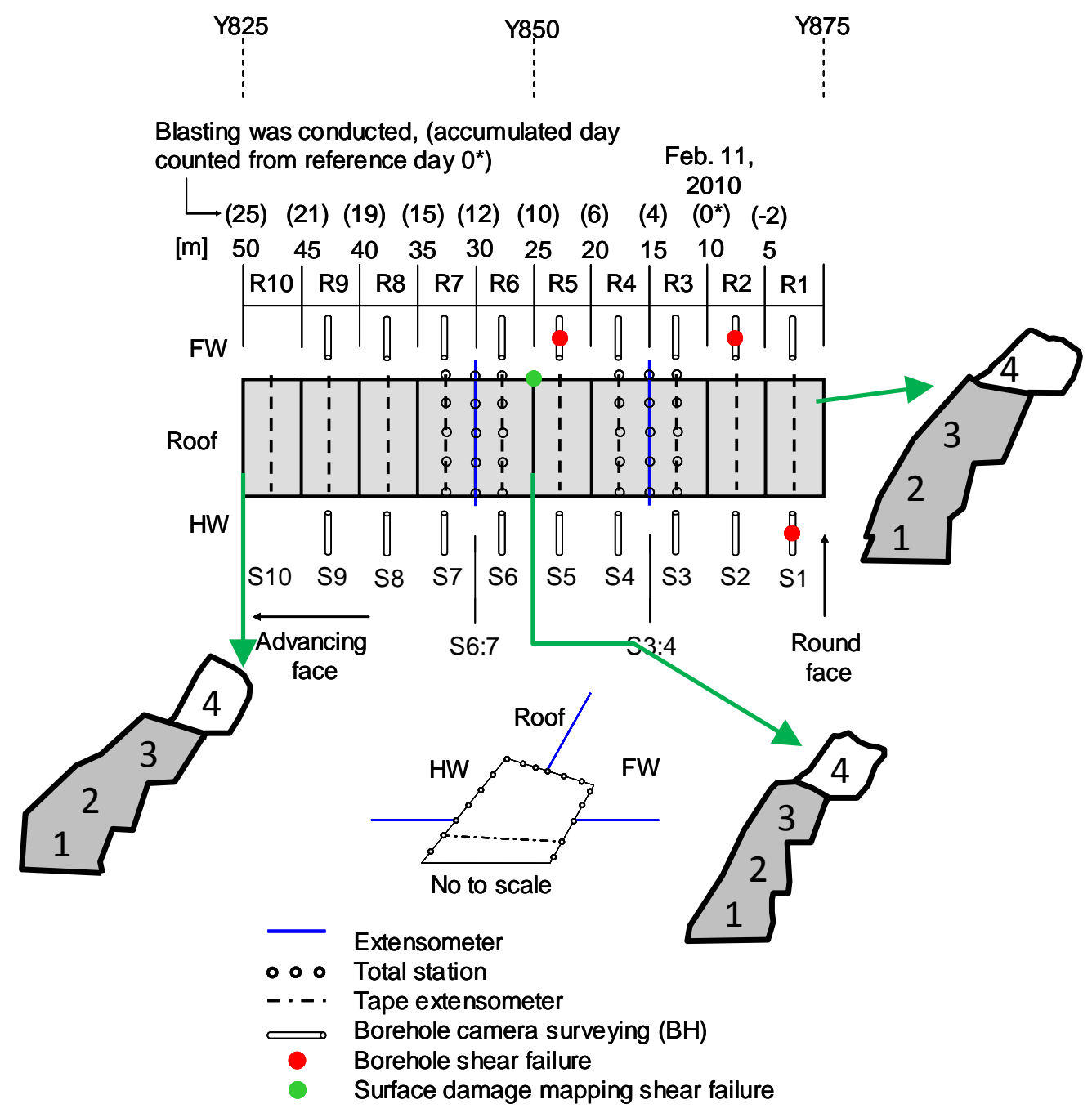

Figure 5 Monitoring details for cut \#4

The deformation pattern of the stope is shown in Figure 6; a vector represents the deformation between two measurements. Borehole camera surveying and surface damage mapping were carried out in cut \#4. 
The boreholes, length: $2.7 \mathrm{~m}$ from the stope boundary and diameter: $38 \mathrm{~mm}$, were surveyed in nine sections (BH1-BH9) of the HW and FW on 11 February, 15 February, 20 February, 11 March, and 25 March 2010. The first seven boreholes (BH1-BH7) in the FW showed fracturing and in $\mathrm{BH} 2$ a shear failure was observed (Figure 7). Damage mapping of the FW revealed surface fracturing of the shotcrete.

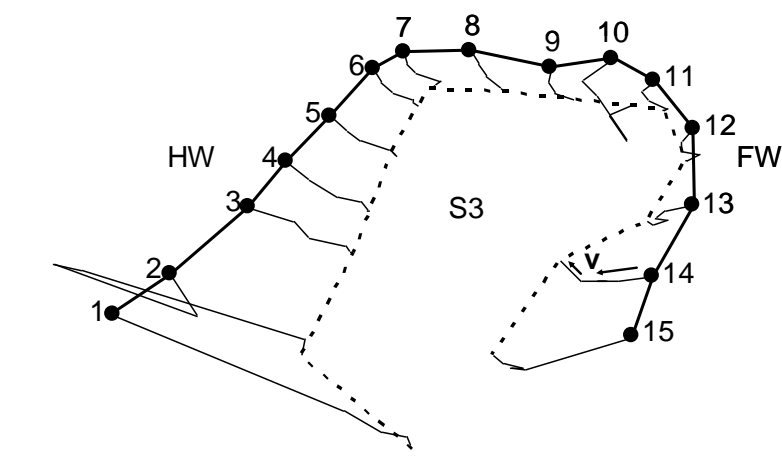

$\begin{array}{lll}-\quad \text { Measurement point } & \text { Before monitoring } \\ - \text { Vector }(\mathbf{v}) \text { indicating direction } & \text { After monitoring }\end{array}$
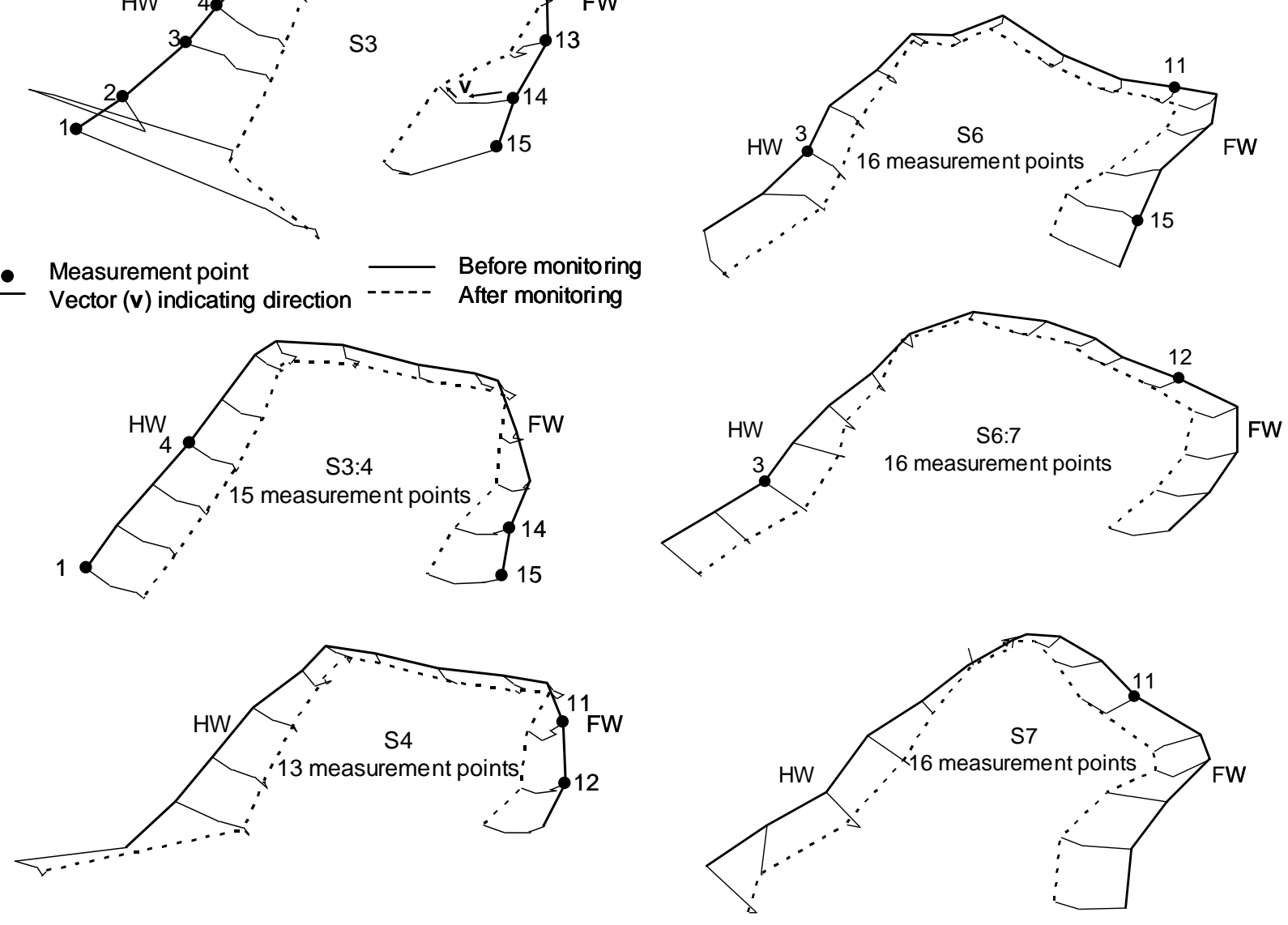

$\underset{\mathrm{Z}[\mathrm{m}]}{L_{X[\mathrm{~m}]}} \stackrel{[1 \mathrm{~m}]}{\stackrel{\text { Scale }}{\text { Vertical overview }}}$

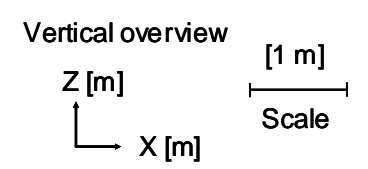

Figure 6 Deformation pattern of the stope at $S_{3}, S_{3}: 4, S_{4}, S 6,56: 7$ and $S_{7}$ by means of total stations. Measurement points and vectors are illustrated for $\mathrm{S}_{3}$ and measurement point 14

The FW was sliding into the opening between $\mathrm{S} 5$ and $\mathrm{S} 6$. The sliding was similar with respect to the pattern and shape of the general failure mechanisms of the FW (Figure 3). These failures are denoted 'observed borehole shear failure' (Figure 7). The convergence between the HW and FW, calculated from the tape extensometers at S1, S2 and S5, was used to evaluate the deformation related to the borehole shear failures. Since borehole and damage mapping of the FW were not done every day, it was not possible to determine the critical deformations defining the onset of shear failure. Further evaluation of the data showed that the shear failures, for example, in BH2-FW (Figure 7), developed with time.

The largest deformations in a monitoring profile occurred when the third round after installation was blasted. The accumulated convergence in the stope was considerably less than that of a typical cut in a stope in this orebody. The explanation to this is probably a combination of two factors: (i) the horizontal offset of cut \#4 relative to cut \#3, resulting in geomechanical conditions similar to the first cut of a stope; 
and (ii) a pyrite lens in the FW. Since the pyrite is stiffer and stronger than the weak alteration zones consisting of chlorite and talc, it has probably reinforced the FW. Other observations were: (a) the HW boundary of the stope showed tendencies of a bending failure while the failure of the FW was a clear shear failure which is in agreement with the general failure behaviour of the Kristineberg Mine; (b) the convergence when shear failure was observed in the inspection boreholes was in the range of 44 to $62 \mathrm{~mm}$; (c) the largest deformation related to bending $(37 \mathrm{~mm})$ and shear $(40 \mathrm{~mm})$ failure was measured in one instrumented section, S3; (d) the deformations in the roof indicated that it was punched into the FW; and (e) the lack of geologic information made it difficult to link the failure mechanisms to the geology of the stope.
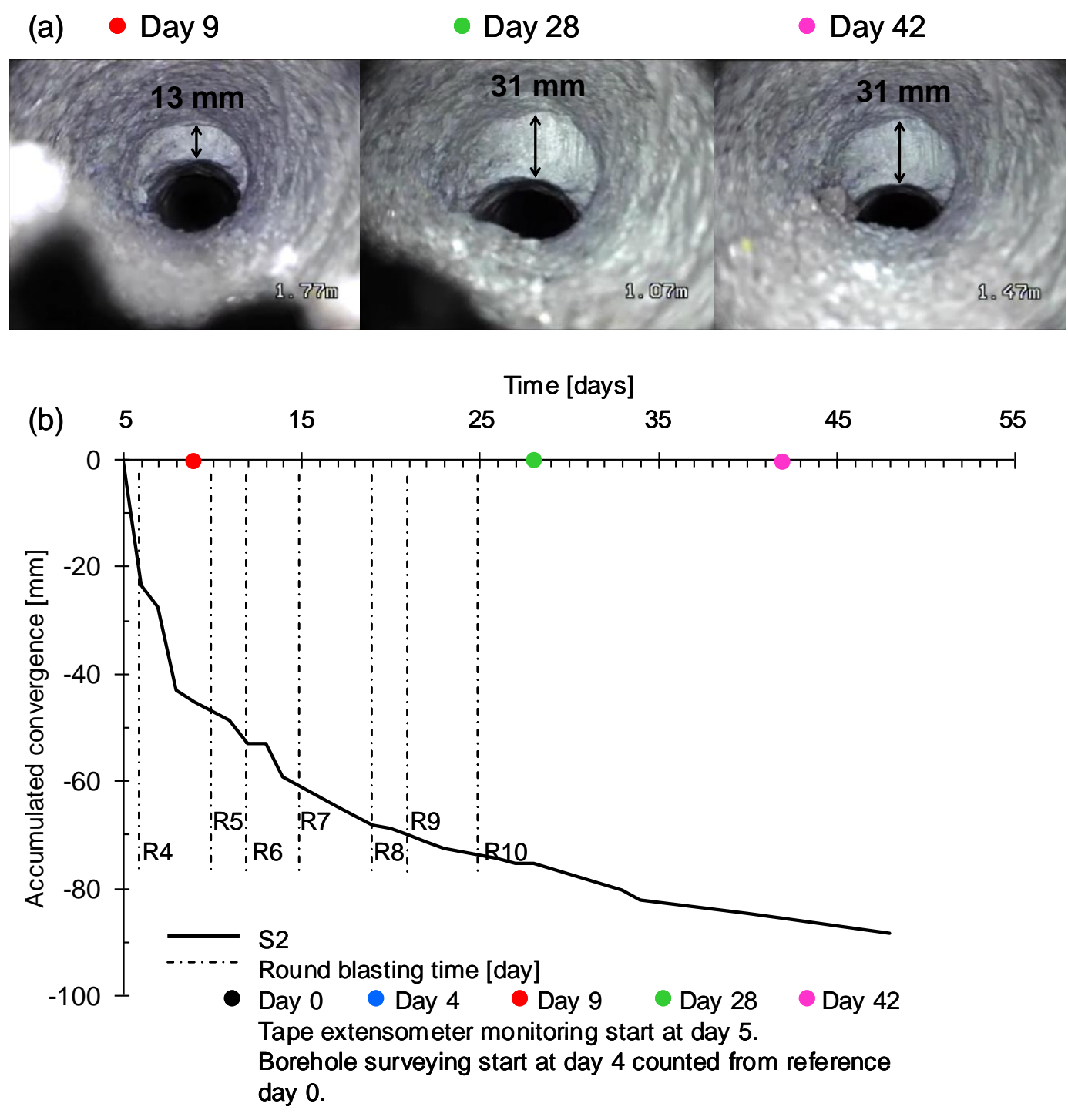

Figure 7 (a) Borehole shear failure $\mathrm{BH}_{2}-\mathrm{FW}$; (b) Accumulated tape extensometer convergence with respect to monitoring time at $S_{2}$. Round face location with respect to time is indicated. Note: reference day o was used

One of the objectives of the monitoring was to investigate the performance of the D-bolt. Unfortunately the results did not clarify the difference in performance between the D-bolt and the rebar, this is because of (i) the instrumented bolts did not work as planned, and (ii) the relatively small deformations monitored in the stope during cut \#4. The deformations monitored in the different profiles showed no significant difference implying that one bolt type would be more effective than the other. 


\subsubsection{Monitoring in stope J10-3 cuts \#5 and stope J10-4, cut \#1}

Since the deformations of stope J10-3, cut \#4 was smaller than expected and no difference between the bolt types had been detected, it was decided to conduct additional monitoring. In cut \#5 a small-scale test was carried out with only D-bolts installed in two rounds. These were compared with two rounds with only D-bolts. The results from this test gave interesting results with large deformations in the test sections (Table 2). At that time it was difficult to draw any conclusions whether less rehabilitation in the sections with D-bolts was due to the geology or the performance of the D-bolt. To find an answer to this question, a more extensive measurement campaign was conducted in stope J10-4, cut \#1 (the level above the cut \#5, stope J10-3). The bolt type installed was alternated every section between standard rebar and D-bolt. Five sections were instrumented: two rebar and three D-bolt sections. The instrumentation comprised bolts with different installation principles combined with laser scanning of the profiles and video inspection of boreholes (Figure 8). In addition, extensive damage mapping of the rock support as well as documentation activities were conducted in the stope.

Table 1 Results from stope J10-3, cut \# 5

\begin{tabular}{lll}
\hline & D-Bolt Section & Rebar Section \\
\hline Rock mass quality & Very bad (talc and chlorite-schist) & $\begin{array}{l}\text { Acceptable (cordierite-quartzite } \\
\text { and chlorite-schist) }\end{array}$ \\
Convergence & $160 \mathrm{~mm}$ & $95 \mathrm{~mm}$ \\
Shotcrete failure & Small cracks in the abutment & Extensive cracking in the wall and \\
& & No loaded bolts, some were bended which \\
Bolt failure & indicate shearing of the footwall & One bolt failure (failed in the \\
& thread, some loaded bolt plates)
\end{tabular}

The result from the measurements in cut \#1, stope J10-4 showed that: (i) the deformations in the D-bolt profiles were greater than those in the rebar sections, indicating that the D-bolt deforms more than the rebars, and (ii) the number of rehabilitations were not fewer in sections with D-bolt than in sections with rebars.

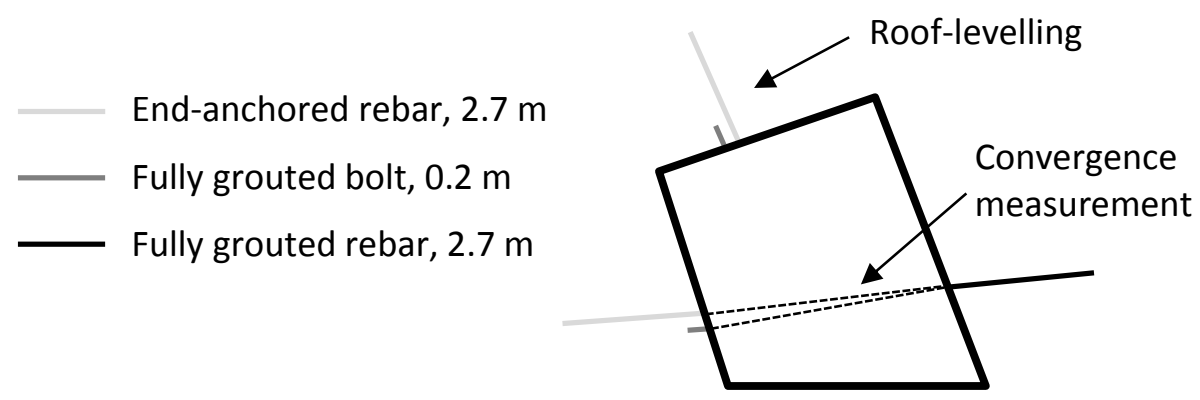

Figure 8 Instrumentation of stope J10-3, cut \# 5 and stope J10-4, cut \#1

\subsection{Malmberget Mine}

Loussavaara-Kiirunavaara $A B$ ( $L K A B)$ was founded in 1890. However, the history of this mining region dates back to 1660s when the first ore sample was collected. Today, LKAB operates two underground mines: Kiirunavaara and Malmberget. The Malmberget Mine comprises some 20 orebodies of which about half of them are in production today. The mine is located in the municipality of Gällivare, Norrbotten county in northern Sweden. The ore consists mainly of magnetite. Today mining is conducted at $600-1,000 \mathrm{~m}$ depth. 
The main mining method is large-scale sublevel caving. The mine is distributed over an area of approximately $2.5 \times 5 \mathrm{~km}$ (north-south/east-west). The dip of the orebodies varies between 15 and $75^{\circ}$, with an average dip of $45-50^{\circ}$ (Figure 9 ). The ore field is strongly affected by regional metamorphosis. The volcanites which surround the ore are called leptites. The Norra Alliansen orebody is the largest orebody in the Malmberget Mine with 30\% of the total production of iron ore. It strikes east-west and dips $60^{\circ}$ to the south, has an average width of around $50 \mathrm{~m}$ and daylights. It has a complex geology with a number of ore lenses. The major ore consists of magnetite with smaller amounts of hematite. Zones of biotite are common in the vicinity of the orebody (in the ore contact zone). The Norra Alliansen orebody merges with the Printzsköld orebody at around 1,000 m depth, resulting in an orebody with a total length of $2 \mathrm{~km}$.

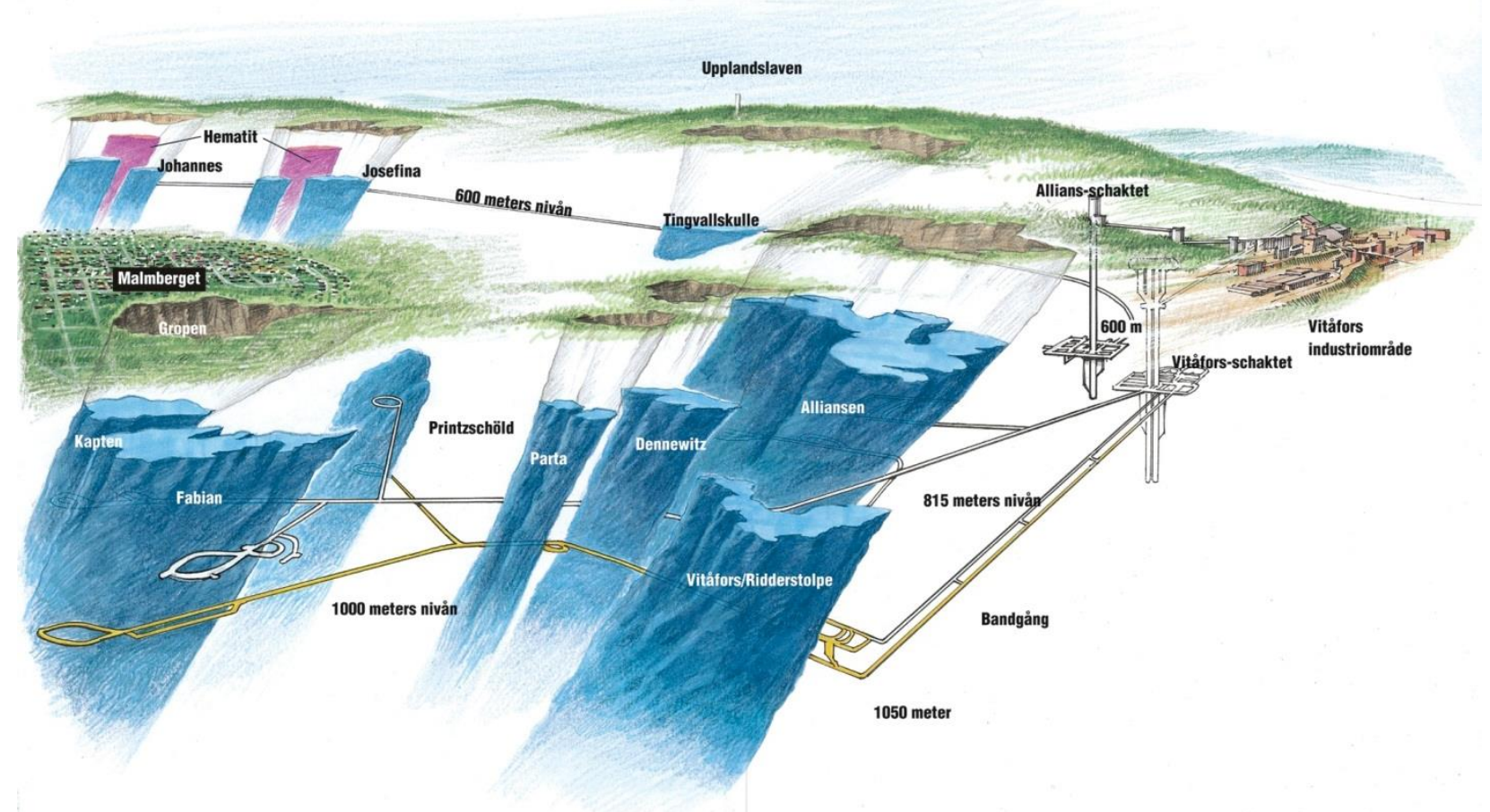

Figure 9 Malmberget Mine (courtesy of LKAB)

\subsubsection{Instrumented area}

The test crosscut (crosscut 4190) is located in an area with serious ground control problems characterised by large deformations and instability (Figure 10). The width of the crosscut is $6.5 \mathrm{~m}$ and the height is $5 \mathrm{~m}$ (Figure 11). Three different sections of the crosscut were prepared, each with a length of approximately $15 \mathrm{~m}$, i.e. five rounds, $3 \mathrm{~m}$ each. The rockbolts in the test crosscut comprised $3.05 \mathrm{~m}$ long Kiruna bolts in the first section, $3.05 \mathrm{~m}$ long Swellex bolts (Pm24) in the second section and $3 \mathrm{~m}$ long D-bolts in the third section, in a $1 \times 1 \mathrm{~m}$ pattern. The bolts were combined with $150 \mathrm{~mm}$ thick shotcrete reinforced with Dramix $35 / 65$ (40 kg/m $/ \mathrm{m}^{3}$ of shotcrete). The sections were instrumented as follows: Section 1: Kiruna bolt, Sentinel bolts and extensometers; Section 2: Swellex bolts and extensometers, and Section 3: D bolts and extensometers. The Kiruna and D-bolts were instrumented with strain gauges, while three Swellex bolts were instrumented with load cells. Five and four pairs of strain gauges were mounted on each Kiruna bolt and D-bolt. Since the strain gauges were configured in pairs, a malfunction of one strain gauge means that that the whole pair is lost. In each test section, one extensometers/convergence profile was prepared by installing five MPBXs (Multi Point Borehole Extensometer) in each section (Figure 12). The extensometers installed in the walls and the roof were 7 and $10 \mathrm{~m}$, respectively, all extensometers had six anchors. The distance between the face and the installed instruments was around $10 \mathrm{~m}$ during face advance. After each blast, laser scanning of the crosscut was carried out. Each section comprised five rounds and profiles, R1-R5. 


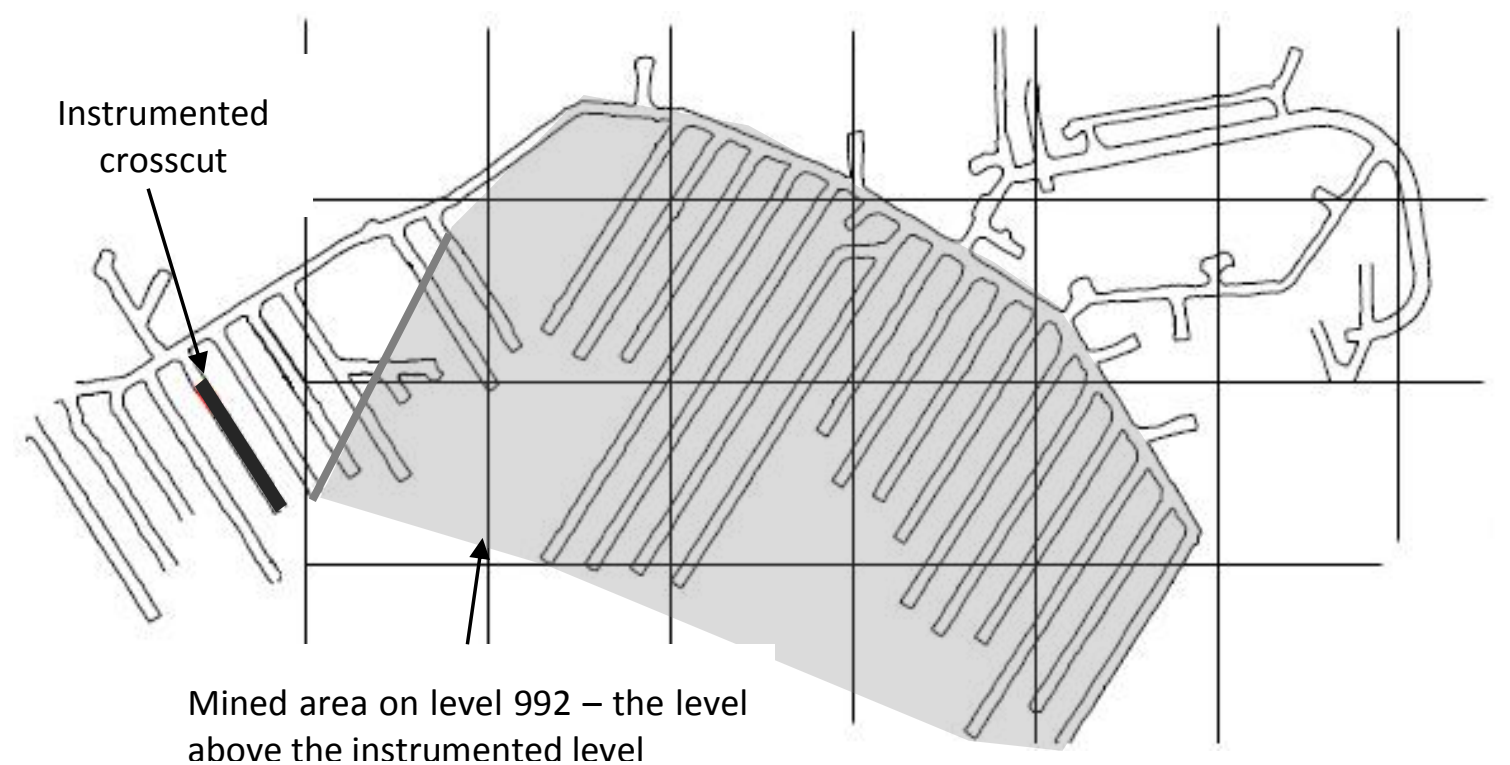

Figure 10 Monitoring area (courtesy of Malmberget Mine)

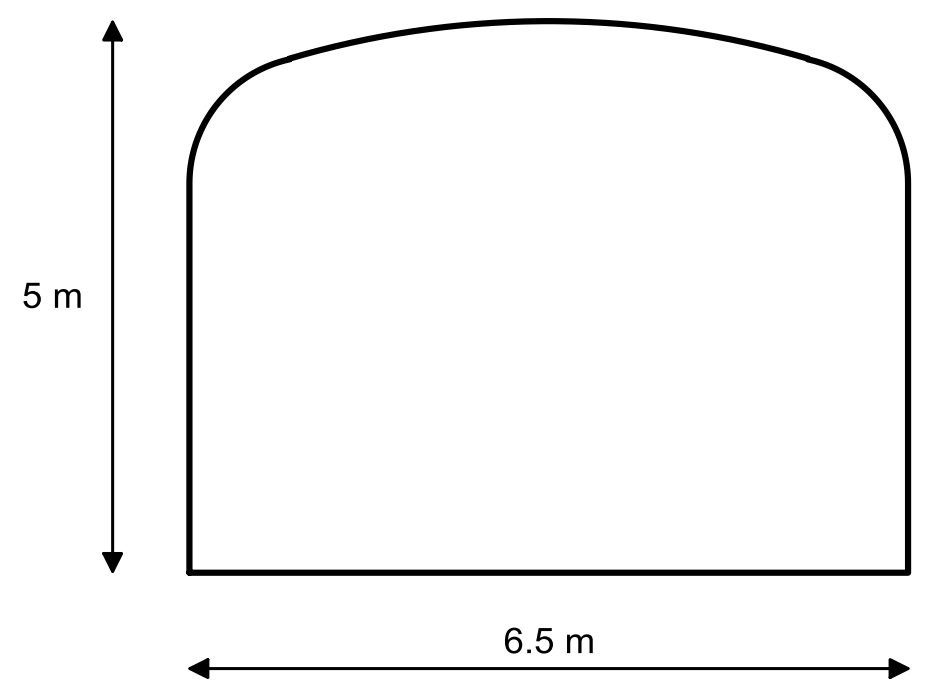

Figure 11 Cross-section of the instrumented crosscut 


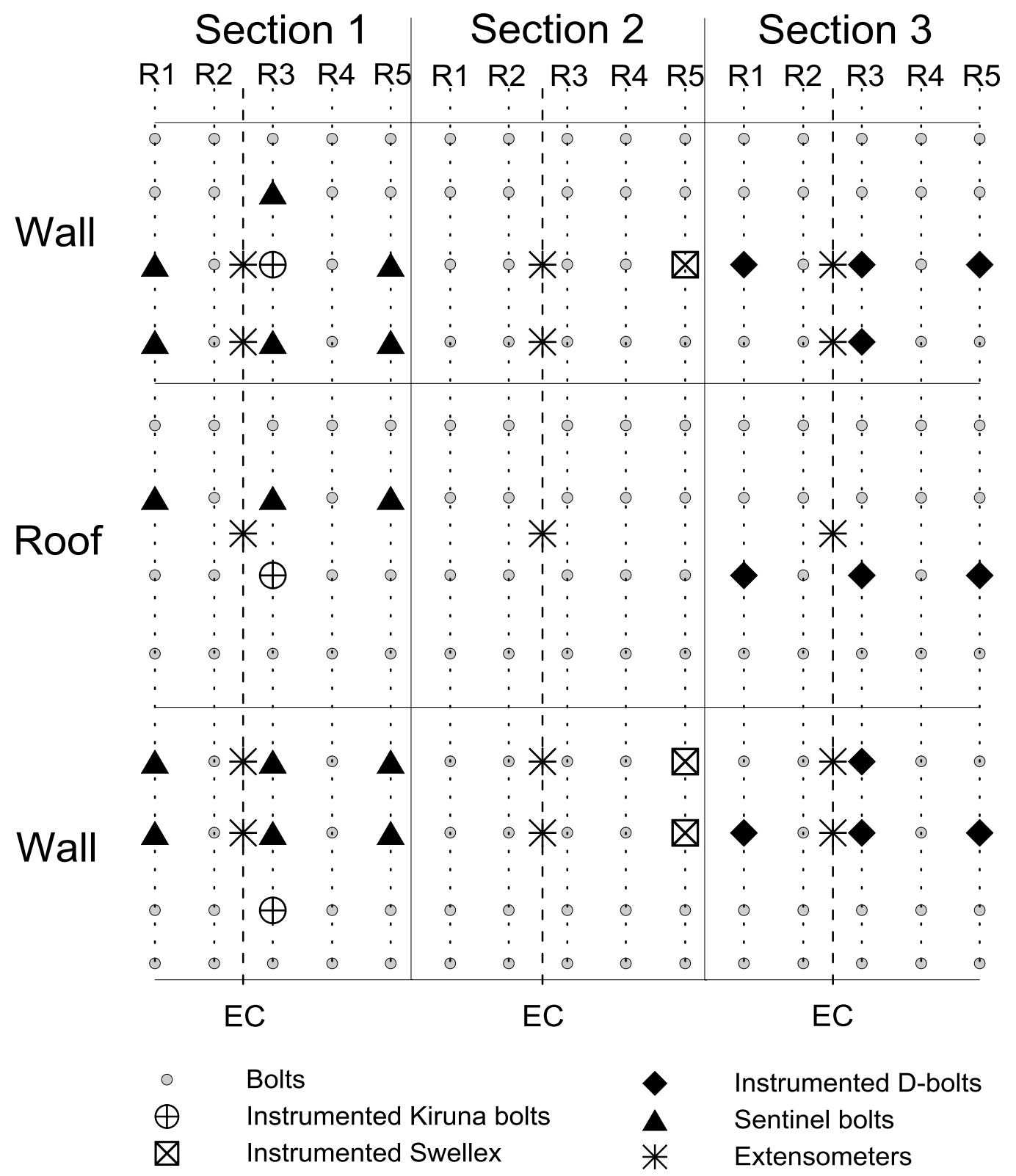

Figure 12 Instrumentation in the crosscut

The monitored displacements and convergences to date are not as high as expected. The largest displacement measured by extensometers was around $45 \mathrm{~mm}$ in Section 3 on the right shoulder of extensometer profile, while the largest convergence measured using a tape extensometer was around $4.5 \mathrm{~mm}$ in the same section. Unfortunately it is not possible to draw any conclusion about the load distribution in the instrumented bolts since the strain gauges were damaged and/or the strains measured were inconsistent. It was only possible to evaluate the results from three instrumented bolts by following the procedures described by manufacturers. For further evaluations justification, judgement and assumptions are needed. Based on these bolts the axial load in the bolt can be as high as $220 \mathrm{kN}$ based on the measured strains on the left sidewall of third round in Section 3. The small deformations may be due to a rock mass which is stronger than expected and/or that the mining is too far away from the crosscut (Figure 10). Based on experience of mining in this area, the largest deformation is expected when mining is conducted along the crosscuts closest and one level above the instrumented crosscut. This will, according to the latest information, occur in March 2013. 


\section{$3 \quad$ Numerical analyses}

\subsection{Analysis of field cases}

The ore and ore contact zone is often characterised by a highly complex geology with large variation in rock mass properties within a relatively limited volume. The identification/definition of the geotechnical domains and their properties is difficult due to limited information from drilling (and other sources). As diamond drilling is expensive it is often focused solely on defining the ore boundaries. In this paper only the modelling of Tests $1(a$ and $b$ ) are addressed.

\subsubsection{Kristineberg case - Test 1a}

The available geological information was obtained from (i) exploration drilling (Figure 2), and (ii) mapping of the roof and the face after each round of blasting. Attempts were made to develop a geological model for rock mechanics analyses, based on geological information from the exploration drilling and other geological information about the Kristineberg Mine. The interpretation of the site geology was done by using the knowledge of the ore genesis in the mine. The mineralisation and weathering pattern show that the geological structures were in place before mineralisation occurred. Therefore, the first element of the geological model is the geological structures. The orebody can later be superimposed on the structural model. The basic interpretation of the genesis of the J-orebody can be summarised in lay person's logic as follows:

- Stage 1: formation of the quartz-cordierite.

- Stage 2: initiation and propagation of structures.

- Stage 3: flow of hot fluids through the structures carrying sulphide minerals and concentrating them along the structures.

- Stage 4: the alteration of the rock walls continues. The cordierite is probably replaced by chlorite to form chlorite-quartz, which then altered into sericite-quartzite or talc-schist.

This interpretation, combined with borehole logs and maps of round faces, were used to construct the geology for the numerical models. Based on this interpretation, geological models were constructed for three profiles: 825,850 and 875 (Figure 2). The following conclusions can be drawn from the attempts to model the rock mass behaviour based on the interpreted geology:

- It can be confirmed that the geology of the FW and HW plays an important role for the stability of the stopes. For example, the presence of talc and its spatial characteristics is critical for the overall stability.

- It is also evident that the progressive mining of cuts tends to have an important effect on the deformations. This is observed in the model of the profile 875 . This behaviour has to be further investigated.

- When a thin layer of talc is exposed at the stope boundary it bends before failing in tension.

- Thick layers of talc in the HW appear to bulge causing large deformation but no failure. In this case, the bolts are punched into the rock and the shotcrete shows a bending failure.

- If two or three layers of talc appear in the wall the depth of extensive deformation is greater than the bolt length.

\subsection{Conceptual analysis of field sites}

In order to study the effect of other geological factors, e.g. folding, faulting, thickness and position of weak zones with respect to the stope walls and the interaction between the rock support and the rock mass, conceptual models were developed and analysed. Two approaches were chosen in our work, i.e. 
identification of typical geological/geotechnical scenarios (Figure 13), and the use of probabilistic analysis. Both methods will be used in the next stage of the project. Test $1 \mathrm{~b}$ will only be modelled using conceptual models employing geological/geotechnical scenarios typical for the host rock in the ore contact zone around the Norra Alliansen orebody. The conceptual models for the Kristineberg Mine are based on the scenarios presented in Figure 13. Furthermore, the effect of folding/faulting will also be addressed.

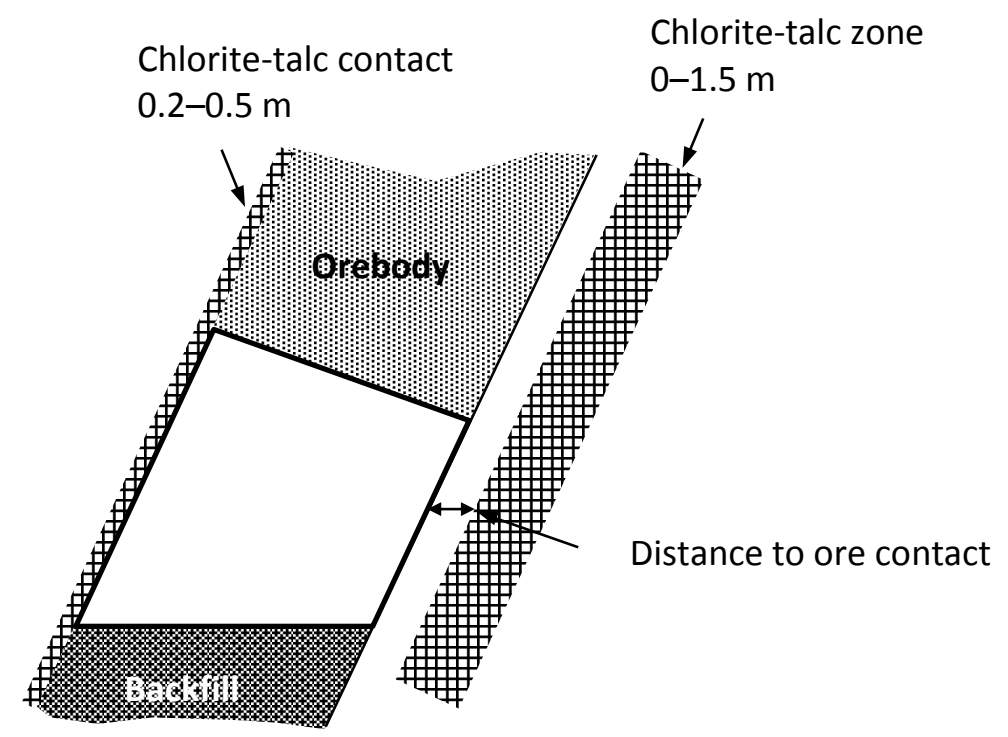

Figure 13 Typical geomechanical scenarios in the Kristineberg Mine

The conceptual models for the Norra Alliansen orebody in the Malmberget Mine based on typical scenarios are presented in Table 3 and Figure 14. The FW drift has been chosen for these studies since it is normally more affected by mining due to stress re-distributions pushing the stresses beneath the bottom of the production level. Also the FW drift is of greater importance for the production on a level than the crosscuts. The drift is located at a realistic typical distance of $50 \mathrm{~m}$ from the ore contact in the model. Local models of a FW drift will be studied. The boundary stresses are obtained from global analyses of the whole mine. The conceptual analyses of the Kristineberg and the Malmberget mines are still in progress. They will be reported during the spring of 2013.

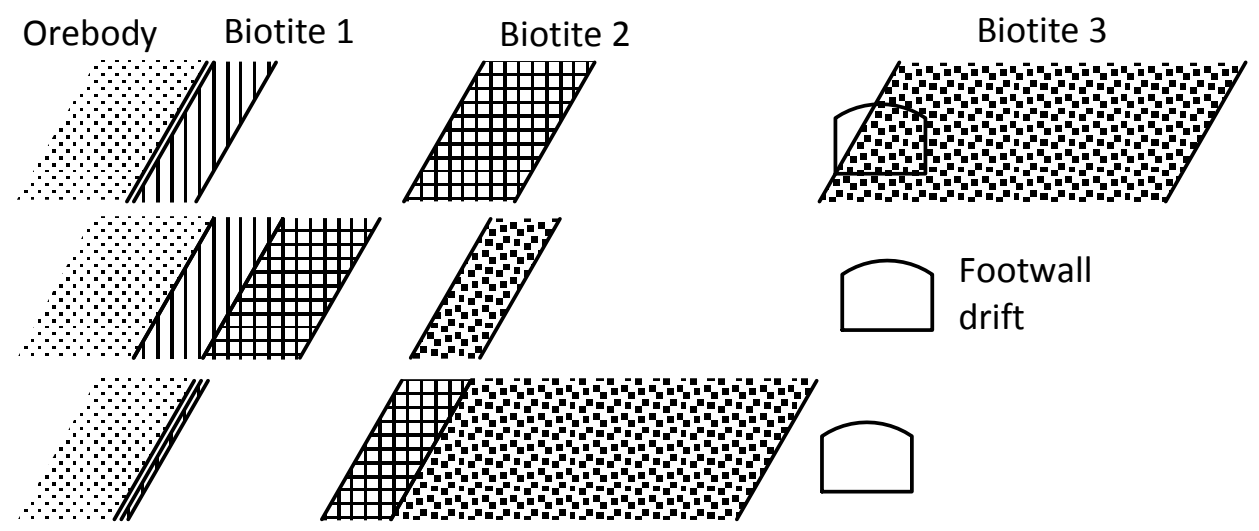

Figure 14 Three possible scenarios in the Malmberget Mine 
Table 3 Typical geomechanical scenarios in the Malmberget Mine

\begin{tabular}{ccccc}
\hline Biotite Zones & Distance From the Ore Contact $(\mathrm{m})$ & Thickness $(\mathrm{m})$ & UCS $(\mathrm{MPa})$ & $\sigma_{\mathrm{t}}(\mathrm{MPa})$ \\
\hline Biotite 1 & $0.5-5$ & $0.5-5$ & $5-30$ & $0-5$ \\
Biotite 2 & $5-20$ & $5-10$ & $30-50$ & $5-10$ \\
Biotite 3 & $20-50$ & $20-30$ & $50-80$ & $10-20$ \\
\hline
\end{tabular}

\subsection{Rock support-rock mass interaction}

Since the interaction between the rock support and the rock mass was the focus of the project, the rock support elements, the rock support system and the interaction have to mimic the real behaviour in detail. There are at least two factors which have to be checked to satisfy these conditions, i.e. the constitutive models for the rock support elements and the effect of the geometry of real openings. Numerical analyses of laboratory tests (punching tests and shear tests), and a study of the constitutive models for rock support elements provided in the Itasca codes have been carried out. This study has shown that FLAC and UDEC provide constitutive models for rock support elements which are performing similar to real rock support elements, with some exceptions. It is not possible to simulate shear failure of rockbolts, and the interaction logic between different structural elements of a support system is not fully developed. More work will be done within this area, including an inventory of rock support models in other software packages.

\subsection{Unevenness}

Although shotcrete has been widely used as rock support in mining and civil engineering projects, the support mechanism provided by a shotcrete lining is not well understood and the design still rests on the empirical methods to a great extent. The main reason is that the interaction between the rock mass and the shotcrete is very complex and is influenced by a number of important factors, such as the unevenness of the rock surface, the properties of the interface between the rock mass and the shotcrete, the disturbed or damaged zone around the opening, the properties of discontinuities, and the surrounding rock and shotcrete lining (Malmgren and Nordlund, 2008). Traditionally, the theoretical design of shotcrete support has been based on the assumption that the tunnel surface is smooth and circular and the shotcrete lining acts as a structural arch or as a series of beam elements acting between point supports provided by rockbolts or cables. Correspondingly, the shotcrete lining is numerically simulated by using beam elements with a smooth interface between rock and shotcrete. However, it is inevitable that the tunnel perimeter becomes uneven when a tunnel is excavated by a drill and blast operation or in jointed rock mass conditions. Hoek and Brown (1980) pointed out that, in the case of a thin shotcrete lining, the abrupt changes in the tunnel profile can induce high stress concentrations in the shotcrete lining, causing cracking and a serious reduction in the load bearing capacity of the lining. Chang (1994) investigated the influence of the unevenness of tunnel surfaces on the support effect of shotcrete for weak rock conditions by performing a large-scale laboratory test.

Malmgren (2005), and Malmgren and Nordlund (2008), studied the effect of the unevenness of the excavation surface of a drift in the Kiirunavaara underground mine on the performance of the shotcrete lining by using the 2D Universal Distinct Element Code (UDEC). The surface unevenness was simplified to a saw-tooth shape. By varying the amplitude in the range $0-0.3 \mathrm{~m}$, it was possible to investigate the effect of the unevenness of the surface. The wavelength was kept constant at $2.5 \mathrm{~m}$. In the base case the amplitude was set to $0.15 \mathrm{~m}$. The input values of the amplitude and the wavelength were based on measurements of the shape of drifts and crosscuts in the mine. The studies showed that the number of tensile failures in the shotcrete and the number of shear/tensile failures at the interface were highly affected by the unevenness of the surface, even though the amplitude was small. The conclusion from Malmgren's (2005) work was that the single most important factor for the behaviour of the shotcrete and the shotcrete-rock interaction was the unevenness of the surface of a drift (walls and roof). While a smooth shotcrete layer behaved like an arch, a surface with the slightest unevenness showed no arch action and local failures at apexes and 
depressions of the rock surface. Son and Cording (2007) carried out UDEC analyses which gave similar results. Lee (2010) used a sinusoidal function to simulate the uneven circular tunnel perimeter and investigated its effects on the rock-shotcrete interaction by using FLAC3D. The results showed that the axial stress in shotcrete was highly dependent upon the unevenness, and that the axial stress of the irregular shotcrete deviates from that of theoretical solutions. The shear stress was highly influenced by the wavelength of liner irregularity. As the wavelength decreased, or the liner irregularity increased, the shear stress at the interface of the irregular shotcrete became higher.

The laboratory tests carried out by Chang (1994) were analysed using the Distinct Element Code, 3DEC (Figure 15). In order to consider the complex unevenness, the shotcrete lining was modelled by deformable zones using a very dense radial grid with five zones over the thickness $(1 \mathrm{~cm})$. The choice of five zones was based on comparison of numerical simulations of a cantilever beam with different zone numbers and analytical solutions. The result showed that the numerical error was reduced to less than $6 \%$ when the beam was discretised with more than five zones over the thickness.

The rock and the shotcrete lining were modelled using a linear elastic - perfectly plastic Mohr-Coulomb model. The mechanical properties of the rock material were obtained from Chang (1994). The cohesion was calculated by assuming a friction angle of $30^{\circ}$. The normal and shear stiffness for the interface were calculated by assuming that the stiffness of the interface was proportional to the modulus of the adjacent material. With respect to the modulus ratio and the tested value of joint stiffness (Saiang et al., 2005), the joint normal and shear stiffness were calculated. The input data is listed in Table 4.

Table 4 Input properties

\begin{tabular}{lccc}
\hline Item & Rock & Shotcrete & Rock-Shotcrete Interface \\
\hline Young's modulus (GPa) & 100 & 4,000 & \\
Poisson's ratio & 0.2 & 0.25 & \\
Cohesion (MPa) & 0.3 & 7.0 & 0.45 \\
Friction angle ( $\left.{ }^{\circ}\right)$ & 25 & 30 & 30 \\
Tensile strength (MPa) & 0.15 & 5.4 & 0.45 \\
Joint normal stiffness (MPa/m) & & & 1,400 \\
Joint shear stiffness (MPa/m) & & & 5.6 \\
\hline
\end{tabular}

The analysis showed significant differences in behaviour between a smooth surface and an uneven surface. The 2D unevenness constitutes the worst case, but the 3D unevenness gives a similar behaviour of the shotcrete lining and the interaction between the rock and the shotcrete (Figure 16).

The numerical analyses and the laboratory tests by Chang (1994) showed that shotcrete sprayed on a smooth surface of a circular tunnel has a higher supporting capacity than that on simply waved and doubly waved tunnel surfaces. This conclusion can be drawn from the development of failure (yielding) in the shotcrete, failure of the rock-shotcrete interface and the rock deformation. The weak parts of the shotcrete are the apexes and bending failure can be expected. At the local depressions, normal stress concentrations are induced at the interface between the shotcrete and the rock, thus improving the supporting effect. Furthermore, shotcrete on a doubly waved surface of a circular tunnel has better support capacity than that of a simply wave tunnel surface. The tunnel in this analysis had a circular cross-section and the external in-plane stresses, i.e. virgin stresses, were equal, i.e. hydrostatic conditions. Therefore, the main support mechanism of the shotcrete is a structural ring. For other tunnel shapes, the effect of the unevenness need to be further investigated. The results also show that the interface properties are crucial for the performance of a shotcrete support. 


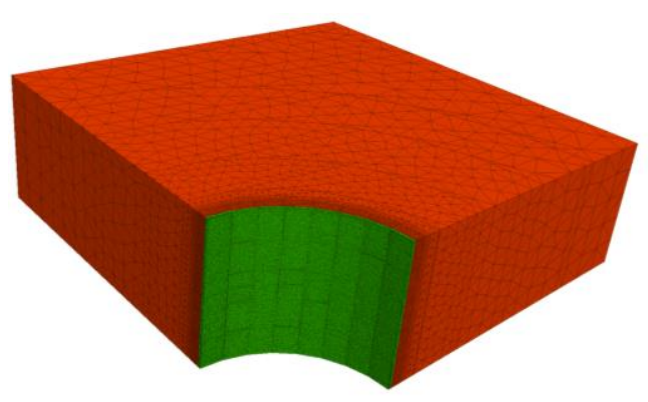

(a)
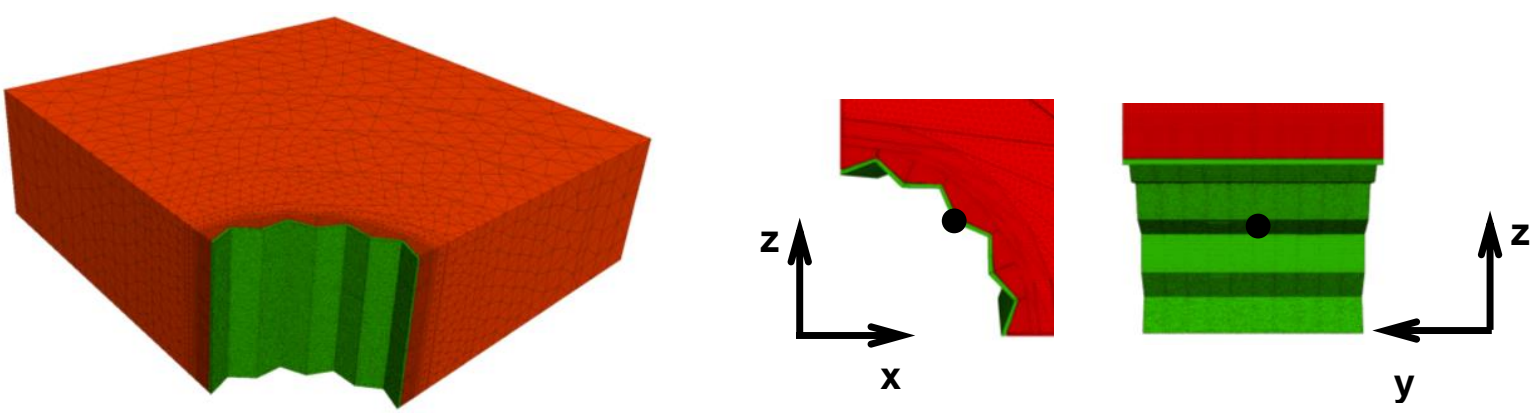

(b)
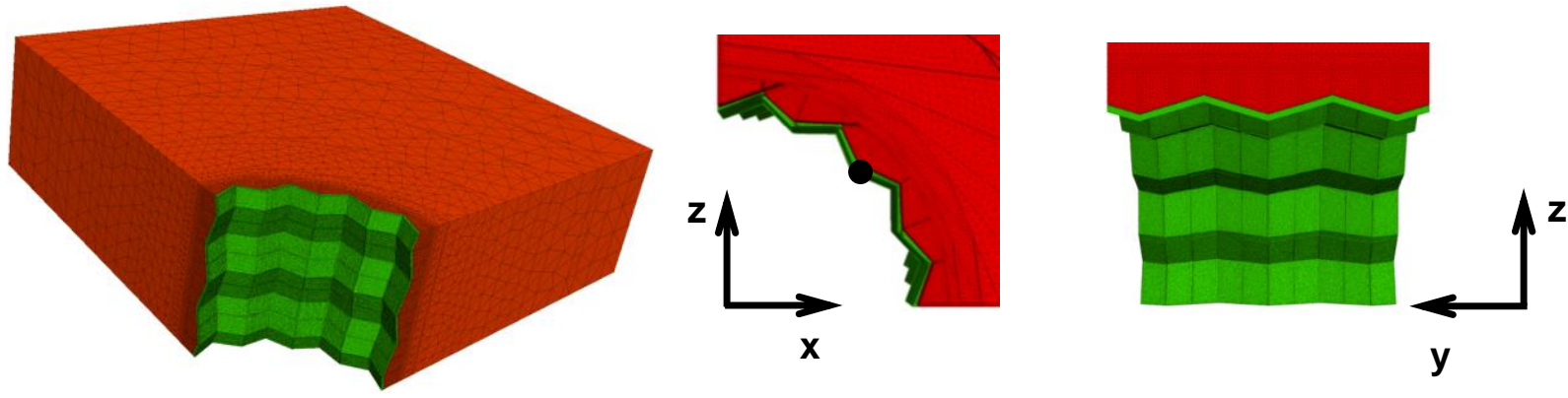

(c)

Figure 15 Numerical models of the laboratory tests by Chang (1994)

The influence of unevenness on the support capacity of the shotcrete is affected by the modulus ratio between shotcrete and rock. If the rock has a low stiffness, the modulus ratio is high and a higher amount of the stresses will be carried by the shotcrete than for the case of a stiff and hard rock. Hence, for rocks with low stiffness and strength, stress concentrations will build up in the interface and in the shotcrete and induce either local interface and/or shotcrete failure. A strong and stiff rock mass on the other hand results in a better performance of the shotcrete since the rock carries its own load.

\section{$4 \quad$ Discussion and conclusions}

The project has revealed a large number of problems and questions that have to be solved before all the details in the rock support-rock mass interaction can be studied and evaluated, and a new methodology for rock support design can be developed. Some of these problems have been solved and ideas how to solve some of the other problems have been gained from the different sub-projects. Since the research programme will continue for a number of years, more progress is likely.

Field studies are very important for the understanding of the rock mass and rock support behaviour. Since the rock mass behaviour depends on its properties, it is important to be able to identify the geology in the test area and develop a geomechanical model. This can be a difficult task since the ore and the surrounding rock mass is often complex and difficult to describe in detail, and also due to a lack of available information. This situation was obvious in two of our tests: Tests $1 \mathrm{a}$ and $1 \mathrm{~b}$. It was difficult to find the 'right' site for the 
monitoring programmes and in a few occasions, new sites had to be chosen. This was due to serious ground control problems during development, the ambition to find a site with typical behaviour and changes in the production schedule. The criterion used to choose the instrumented sites was that large deformations and development of visible failure should take place during the monitoring programme. Despite the thorough investigation before choosing the sites, it was not evident in the Kristineberg test that the orebody was folded or faulted between the third cut and the cut \#4. The mapping of the roof of cut \#3 indicated that the orebody continued along the same dip as the first three cuts. The fold/fault was located only a few decimetres above the floor of cut \#4 and displaced the stope almost one stope width horizontally. The deformations and the extent of failure were therefore not representative for a typical cut (above the bottom cut) in this orebody. It behaved similar to a bottom cut.

Smooth

Plastic Region on Shotcrete Surface
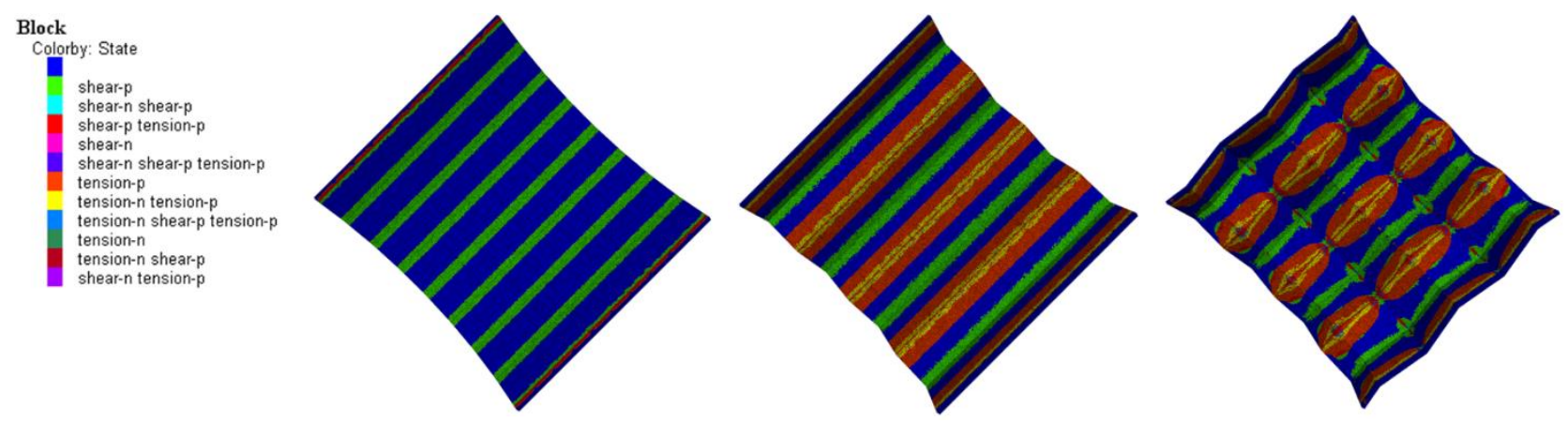

Failure on Interface
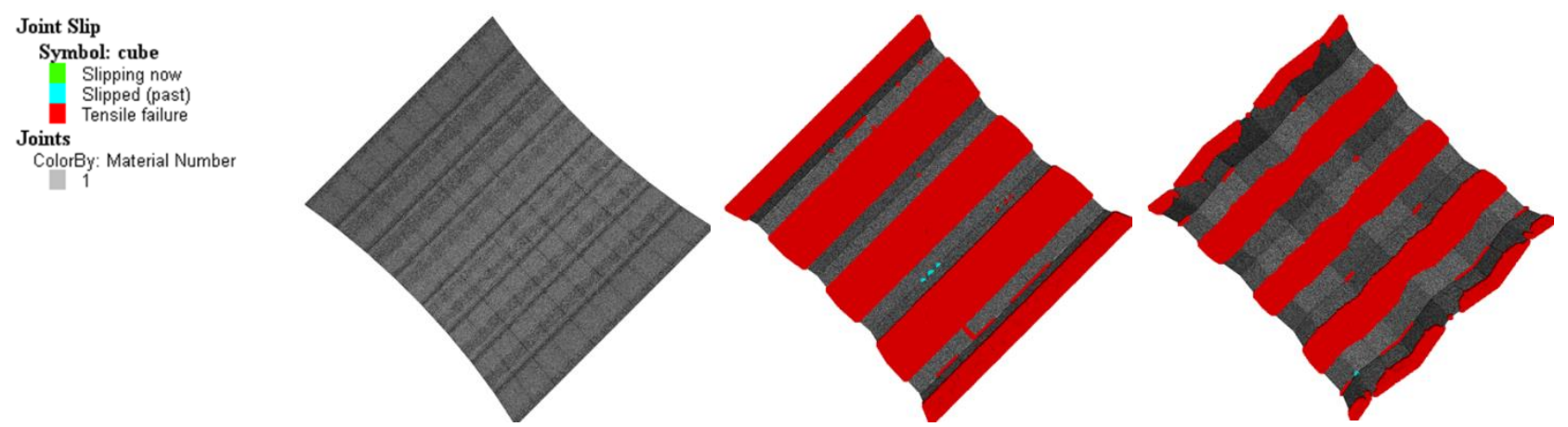

Figure 16 Results from 3DEC analyses

The planning of the monitoring programmes in the Kristineberg and Malmberget Mines (Tests $1 \mathrm{a}$ and $1 \mathrm{~b}$ ) comprised a selection of quantities to monitor instruments and instrumentation pattern. Unfortunately, some of the quantities of interest for the interaction between the rock support and the rock mass were difficult or impossible to measure, such as the interaction between the shotcrete and the rock mass. Tests $1 \mathrm{a}$ and $1 \mathrm{~b}$ were therefore designed to monitor the overall performance.

The numerical analysis of the monitoring sites was done using two approaches: (i) real geology (Kristineberg Mine); and (ii) conceptual models using typical geomechanical scenarios. Preliminary results revealed that the folding changes the stope behaviour from unstable to stable, and that the thickness and position of the weakness zones in the FW and HW govern the stability of the stope. The detailed analysis of the rock support performance and the interaction between the rock support and the rock mass interaction is ongoing and parts of it will be reported during 2013.

The analysis of the effect of the unevenness on the performance of shotcrete support showed that (i) rockbolts should be installed at the apexes of drift surface to reduce the tensile stress concentration in 
shotcrete and also enhance the bond between the shotcrete and the rock surface, and (ii) shotcrete performance and the interaction between the shotcrete and the rock mass observed in the numerical analyses reflects the behaviour in the laboratory tests by Chang (1994). However, this approach (using zoned shotcrete) is not suitable for numerical analyses on a routinely basis due to the large number of zones needed to properly model the shotcrete and the rock mass, and (iii) neither the simply-waved nor the doubly-waved unevenness are good representations of a real rock surface. Even though the doublywaved unevenness is 3D, the nodes in the y-direction are aligned parallel to the axis of the opening, resulting in a behaviour which is similar to 2D. Since drifts often are excavated using drilling and blasting, the rock surface follows the pre-existing joints and the failed rock bridges making it extremely complex. Such surfaces are very difficult to create and analyse in a numerical model. More research is needed in order to assess the effect of real unevenness and to get an idea how to consider this in the rock support design.

The investigation of the constitutive models has shown that there is a need for development before the complete interaction between individual rock support elements, and between the rock support system and the rock mass can be simulated.

The field test in the Kristineberg Mine showed that the difference in performance between the rebar and the D-bolt was only clear when rock mass conditions were characterised by large deformations. The conclusions for the rock support performance were: (i) the deformations in the D-bolt profiles were much greater than those in the rebar sections indicating that the D-bolt deforms more than the rebars; and (ii) the number of rehabilitations were not fewer in sections with D-bolt than in sections with rebars. One conclusion is that the stability of the stope is only marginally dependent on the type of bolt installed as long as shotcrete is used as the surface support.

\section{Acknowledgement}

This research at Luleå University of Technology has been sponsored by Vinnova (Swedish Governmental Agency for Innovation Systems), LKAB, Boliden Mineral AB, Hjalmar Lundbohm Research Centre, Centre of Applied Mining and Metallurgy at LTU and the seventh Framework project $I^{2}$ Mine. The author acknowledges the researchers in his LTU group, and industrial partners Boliden Mineral AB and LKAB. Special thanks are extended to Ping Zhang, Hakan Basarir, Magnus Westblom, Shahin Shirzadegan, Mikael Nilsson, Ulf Nyberg, Andreas Eitzenberger at LTU; David Saiang (LTU and SRK); Kelvis Perez (LTU and Boliden Mineral AB); Per-Ivar Marklund and Daniel Sandström at Boliden Mineral; and Lars Malmgren, Thomas Wettainen, Anders Nordqvist, Thomas Savilahti and Jimmy Töyrä at LKAB.

\section{References}

Chang, Y.T. (1994) Tunnel support with shotcrete in weak rock - A rock mechanics study, Doctoral thesis, Division of Soil and Rock Mechanics, Royal Institute of Technology (KTH), Stockholm, Sweden.

Hoek, E. and Brown, E.T. (1980) Underground excavations in rock, The Institution of Mining and Metallurgy, London, 527 p.

Krauland, N., Marklund, P-I. and Board, M. (2001) Rock support in cut-and-fill mining at the Kristineberg mine, Underground Mining Method - Engineering Fundamentals and International Case Studies, W.A. Hustrulid and R.L. Bullock (eds), the Society for Mining, Metallurgy, and Exploration, Inc., Littleton, Colorado, USA, pp. 325-324.

Lee, S.D. (2010) Numerical analysis for irregular shotcrete on uneven tunnel perimeter, International Journal of Rock Mechanics and Mining Sciences, 2010, Vol. 47(3), pp. 488-495.

Malmgren, L. (2005) Interaction between shotcrete and rock - experimental and numerical study, Doctoral thesis, Division of Mining and Geotechnical Engineering, Luleå University of Technology, Luleå, Sweden.

Malmgren, L. and Nordlund, E. (2008) Interaction of shotcrete with rock and rock bolts - A numerical study, International Journal of Rock Mechanics and Mining Sciences, Vol. 45, pp. 538-553.

Saiang, D., Malmgren, L. and Nordlund, E. (2005) Laboratory tests on shotcrete rock joints in direct shear, tension and compression, Rock Mechanics and Rock Engineering, Vol. 38(4), pp. 275-297.

Son, M. and Cording, E.J. (2007) Ground-liner interaction in rock tunnelling, Tunnelling and Underground Space Technology, Vol. 22, pp. 1-9.

Sundström, R. (2010) Utvärdering av Smart Cable för att se belastning på bergbultar, Master Thesis, Luleå University of Technology. 